\title{
Sustainable transition in small island developing states: Assessing the current situation.
}

\author{
Jean Philippe Praene ${ }^{\mathrm{a}, *}$, Mahéva Payet $^{\mathrm{b}}$, Fiona Bénard-Sora ${ }^{\mathrm{a}}$ \\ ${ }^{a}$ PIMENT Laboratory - Université de la Reunion, France \\ ${ }^{b}$ Department of Building Sciences and Environment - Université de la Reunion, France
}

\begin{abstract}
Transitioning to sustainable energy systems is an overriding challenge for small islands. Indeed, these territories must succeed within the next decades with the objective of energy independence and transitioning to a sustainable situation. In this research, a statistical approach is performed to explore and discuss a comprehensive study on small islands' sustainability from the standpoint of renewable energy. It is about identifying whether small islands are moving toward a sustainability path. Three steps are necessary to achieve this. A principal components analysis (PCA) is first investigated to identify which explanatory variables have a significant contribution on the percentage of data variance. Then, PCA-based hierarchical clustering highlights the island organization in two different years (2010 and 2014). It is a panel of 35 Small Islands Developing States (SIDS) that served as a basis for the PCA and classification. Finally, a sustainability indicator is proposed to qualify the level of sustainability of each group of islands. Sustainability is understood through the lens of the share of renewables, the electricity situation, economic development and geographical localization. The obtained results clearly show that the dynamics of transition is not clearly engaged for the small islands. Most of them have actually become more vulnerable during the 2010-2014 time span.
\end{abstract}

Keywords: Sustainability, SIDS, Renewable energy, Principal components analysis, Composite indicator

\section{Introduction}

Adaptation to climate change is the greatest challenge of our century. Sustainable policies help in reducing the vulnerability of a territory and populations to the effects of climate change. This mainly relates to defining policies on prevention of natural disaster, better build and land-use planning or modernising the infrastructure. Many academic research have focused on the climate change mitigation through the study of renewable energy potential. Futhermore policy recommandation widely suggest renewable technologies deployment and also increase in energy efficiency, [1],[2]. In our society, energy is a crucial point for many economical and development activities. In a context of the rarefaction of fossil resources and frequent economic crises, the strong variations in the short-term energy price and its long-term predictable increase have had an increasing impact, [3], [4]. The UN-DESA ${ }^{1}$ currently lists 57 SIDS (37 UN Members and 20 nonUN) spread over the Caribbean, the Pacific and Africa, the Indian Ocean, the Mediterranean and the South China Sea.These territories are specific, because of their small size (which limits e.g. economies of scale), their remoteness and their high exposure to the consequences of climate warming (like rising water)[5][6][7] [8].In the last two decades, the islands have developed some ambitious energy policy frameworks to switch to renewable power. There recently was a particular focus on SIDS during the COP23 conference,[9]. The

\footnotetext{
*Corresponding author, Tel. +262 692235566

Email address: jean-philippe.praene@univ-reunion.fr (Jean Philippe Praene)

URL: piment. univ-reunion.fr (Jean Philippe Praene)

${ }^{1}$ United Nations - Department of Economic and Social Affairs
} 
report highlights the urgency of action to build resilience in small islands. Islands give the opportunity for a forward-looking basis and suggest directions for a sustainable solution to the problems with which all the territories that will have to face climate change are confronted, [10], [11],[12].

Most of these territories are not connected to any continental electricity network due to their geographic situation. Thus, their geographical context (area, location) induces a high level of vulnerability because of many natural or economic circumstances [13]. An early study investigated by [14] focused on the vulnerability of such remote territories by defining an economic index in order to classify islands and understand their vulnerability level. Oil price volatility is significantly detrimental to electricity generation mainly based on fossil fuel sources, [15]. In 2012, the United Nations reiterated the importance of promoting access to sustainable energy-based production. Indeed, due to their relatively small energy demand, these territories are in a precarious situation. Electricity facilitates economic activity, public health services and education. Thus, the sustainable development of the islands involves three major aspects, which are low environmental impact, economic viability and social acceptance. Many scholars have investigated the concept of energy vulnerability. Most of them have addressed the deployment of renewable energy sources (RES) in the electricity generation mix, [16],[17]. The studies focus on an overview of RES potential and prospective analysis. In line with this, the concept of renewislands was introduced by [18] and highlights the necessity to define methodology tools for decision makers and policymakers to better target development aid. These procedures help to increase the sustainability of the electricity mix.

Sustainable development is currently closely linked to sustainable assessment. This last point is particularly complex to define. Indeed, a sustainable assessment must necessarily be performed to understand whether a territory is really under an energy transition. The definition of an index is not harmonized. This can be easily understood by the various standpoints on the comprehensive information contained within sustainability indicators, [19]. Recent studies have highlighted the importance of understanding what the driving factors of energy transition for SIDS are through the lens of robust energy policy development to promote the potential of renewable sources, [20]. Thus, the question of sustainability must be studied via a dynamic approach measurement, that allow to measure an evolution in time.

The main purpose of this study is to analyze, in a short period, whether a sample of 35 islands is currently engaging in a sustainable energy transition. This paper therefore seeks to examine the degree of sustainability of the islands by a three-steps approach to qualify sustainability:

- Perform a PCA to identify the most relevant variables for defining sustainability.

- Use this PCA-based approach to perform clustering in order to identify the islands that have the same profile.

- Define a sustainability index (SI) mainly based on variables that have a significant influence on the principal components.

The paper begins with an overview of the data collection and the main characteristics of the studied islands. We also focus on the hypothesis that helps us to define the SI. Then, a multivariate data analysis is presented to both reduce the dimension of the data set and identify which variables have a significant influence on the principal components. Based on this first step, hierarchical clustering highlights the main characteristics of the classes of the islands. Finally, using the results of PCA, a multi-regressive model is conducted to define the SI. The study is conducted for two different years, 2010 and 2014, to determine whether any early signs of energy transition in these insular territories could be observed.

\section{Materials and method}

\subsection{Data collection}

This study was conducted on a sample of 35 islands. For convenience, in graph results, the islands are represented by their ISO alpha code, as described in Table 2. The first set of data was initially based on the 57 islands that are on the United Nations SIDS list [21], but a reduction was necessary due to the lack 
Table 1: Data definition and descriptive statistics

\begin{tabular}{|c|c|c|c|c|c|c|c|c|c|c|}
\hline \multirow[t]{2}{*}{ Class } & \multirow[t]{2}{*}{ Variable } & \multirow[t]{2}{*}{ Definition } & \multicolumn{2}{|c|}{ Mean } & \multicolumn{2}{|c|}{ Std. Dev. } & \multicolumn{2}{|c|}{ Min } & \multicolumn{2}{|c|}{ Max } \\
\hline & & & 2010 & 2014 & 2010 & 2014 & 2010 & 2014 & 2010 & 2014 \\
\hline \multirow{2}{*}{ Geography } & ISOL & Isolation index & 450.03 & 450.03 & 1106.79 & 1106.79 & 1 & 1 & 4281 & 4281 \\
\hline & SURF & Surface & 34521.23 & 34521.23 & 88194.08 & 88194.08 & 260 & 260 & 462840 & 462840 \\
\hline \multirow[t]{4}{*}{ Socio-economy } & HDI & Human development index & 0.68 & 0.69 & 0.12 & 0.11 & 0.41 & 0.42 & 0.90 & 0.912 \\
\hline & POP & Population & 1714.86 & 1801.33 & 3048.42 & 3180.16 & 20.47 & 21.1 & 11308.13 & 11379.11 \\
\hline & GDP & Gross domestic product & 15012.80 & 16574.14 & 41291.91 & 48954.18 & 150 & 170 & 236422 & 281367 \\
\hline & URB.POP & Percentage of urban population & 48.51 & 46.19 & 24.32 & 23.87 & 9.1 & 8.6 & 100 & 100 \\
\hline \multirow[t]{4}{*}{ Energy } & ELC.CONS & Electricity consumption & 44745.71 & 45448.57 & 137535.06 & 150290.39 & 0 & 0 & 767600 & 853800 \\
\hline & ELC.HYDRO.PR & Hydroelectricity production & 122.61 & 402.61 & 301.82 & 1771.58 & 0 & 0 & 1430 & 10360 \\
\hline & ELC.RNW & Share of renewable (without hydro) & 13.88 & 14.83 & 30.61 & 31.02 & 0 & 0 & 100 & 100 \\
\hline & ELC.ACCS & Access to electricity (\%) & 81.75 & 84.50 & 26.32 & 25.20 & 6 & 172 & 100 & 100 \\
\hline
\end{tabular}

of information for some of them. The objective of the study is to define an "easy-to-use" index that will be defined with accessible variables. The geographical locations of selected SIDS are shown in Figure 1.

The exploratory analysis was conducted over the 9 quantitative parameters detailed in Table 1 . The guiding idea of the method is to focus on the exogenous variable that could be found for each SIDS through the year.

The first group of data consists of some geographical information. The isolation index, which is the ratio of the exclusive economic zone to the total island area, represents how pronounced the ocean isolation is, $[22],[23]$. Thus, this variable shows the island's remoteness from the principal commercial maritime routes. The second group addresses social and economical information. These parameters focus on the economic dynamism and the level of urban development. Finally, the energy cluster represents the energy production and consumption of each territory. The concept of sustainability could be understood by the energy need and share of renewable sources.

\subsection{Data Analysis}

Principal component analysis (PCA) is a multivariate statistical technique widely used to describe a set of quantitative data. This approach is particularly interesting for performing dimensionality reduction of a data set, [24]. We consider a data set composed of many variables $\mathrm{X}_{j}$. The goal is to create new synthetic variables $\left(\operatorname{Dim}_{i}\right)$ from them. These new variables, called dimensions (Dim), are less numerous than the first but they bring as much information. The information contained in a data set corresponds to the total inertia, that is to say the variability of the data, it contains. The objective of PCA is to identify the directions along which the data variation are a maximum. These directions are the dimensions, also called main components: these are the new variables created to facilitate reading and visualization of the data set. When considering the initial data, each individual (each island) is represented by a vector in a multi-dimensional space (each dimension corresponds to an analysis variable that are described on 1). The ACP proceeds to a reduction of these dimensions by a change of plane: one tries to summarize the data in the least possible dimensions (2 ideally). Each individual (island) is then represented by the projection of the initial vector on the new plane. We then obtain the eigenvectors, which are then used in the analysis and interpretation of the results.

The principal components (Dim) are some macro factors based on a linear combination of the variable set, defined as follows :

$$
\operatorname{Dim}_{i}=\sum_{j} \alpha_{i j} X_{j}
$$

where $\alpha_{i j}$ is the contribution of the exogenous variable $X_{j}$ to the construction of the principal component i. These dimensions are uncorrelated and orthogonal. PCA is also a method frequently used as a regressive model [25]: this is actually a good statistical method to analyze the relationships of several variables to each other. Much research has investigated the definition of an index based on PCA, [26], [27]. Our study aims to define a composite sustainability index (SI), and the model described from the principal components is defined as follows:

$$
S I=1-\frac{\lambda_{1} \operatorname{Dim}_{1}+\lambda_{2} \operatorname{Dim}_{2}+\ldots+\lambda_{j} \operatorname{Dim}_{j}}{\lambda_{1}+\lambda_{2}+\ldots+\lambda_{j}}
$$


Table 2: List of islands and ISO code

\begin{tabular}{lc}
\hline Country name & ISO ALPHA-3 code \\
\hline Antigua and Barbuda & ATG \\
Bahrain & BHR \\
Bahamas & BHS \\
Belize & BLZ \\
Barbados & BRB \\
Comoros & COM \\
Cape Verde & CPV \\
Cuba & CUB \\
Dominica & DMA \\
Dominican Republic & DOM \\
Fiji & FJI \\
Micronesia, Federated States of & FSM \\
Guinea-Bissau & GNB \\
Grenada & GRD \\
Guyana & GUY \\
Haiti & HTI \\
Jamaica & JAM \\
Kiribati & KIR \\
Saint Kitts and Nevis & KNA \\
Saint Lucia & LCA \\
Maldives & MDV \\
Mauritius & MUS \\
Palau & PLW \\
Papua New Guinea & PNG \\
Singapore & SGP \\
Solomon Islands & SLB \\
Sao Tome and Principe & STP \\
Suriname & SUR \\
Seychelles & SYC \\
Timor-Leste & TLS \\
Trinidad and Tobago & TON \\
Saint Vincent and the Grenadines & TTO \\
Samoa & VCT \\
\hline & WSM \\
\hline
\end{tabular}


Figure 1: Geographical situation of selected SIDS.
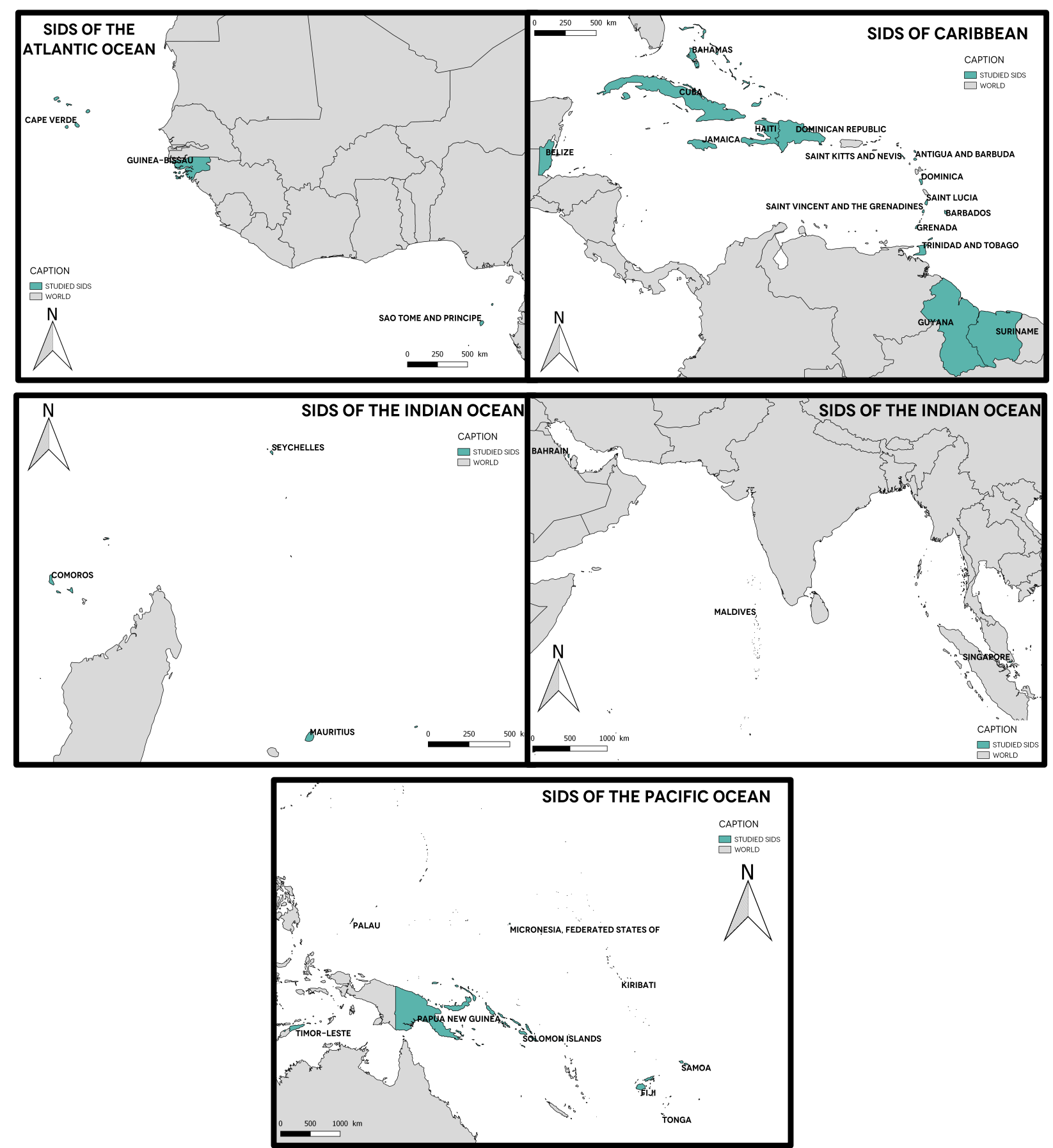

The eigenvalues $\lambda_{i}$ of the correlation matrix $\mathrm{R}$ are obtained by solving the determinant of the following equation $(R-\lambda I)=0$. These eigenvalues represents the variance of the principal component (PC). Then, the dimension could be decomposed by the variables weighted by their contribution to the principal component. The objective of our study is to observe the evolution of the island sustainability between 2010 and 2014 . 
Thus, the data analysis is done in three steps. First, PCA of the original data set is performed. This step allows us to understand the global profile of the islands and select the most significant variables. Then, hierarchical clustering presents the number of classes that characterize the data. This clustering gives useful information on the similitude between islands. Finally, the SI is investigated for the period between 2010 and 2014 to discuss the dynamic of sustainability. This indicator summarizes the overall sustainability information, [28]. The two step analysis (PCA and hierarchical clustering) has been achieved using the FactoMine $R$ package under the $\mathrm{R}$ environment, developed by [29]. The last step is to normalize the value between 0 and 1 .

\section{Results and discussion}

\subsection{PCA results}

This section focuses on the results of the application of PCA to the full data set of 2010. This year is considered the reference year to calculate the regression coefficient for the indicator. The results of the calculation of eigenvalues are depicted in Table 3.

Table 3: PCA results.

\begin{tabular}{llll}
\hline Principal components & Eigenvalue & Variance(\%) & Cumulative(\%) \\
\hline Dim 1 & 3.171 & 31.712 & 31.712 \\
Dim 2 & 2.323 & 23.233 & 54.945 \\
Dim 3 & 1.298 & 12.978 & 67.923 \\
\hline
\end{tabular}

The inertia of the factorial axes suggests that the first two axes of the PCA express $54.9 \%$ of the total inertia of the data set. The fourth component is not considered, as its variance is less than $10 \%$. Thus, the number of variables is meaningfully reduced with a minor loss of information. The first three components will be the macro factors usable later for the regressive index model, as the eigenvalues are greater than 1. This criteria of $\lambda_{i}>1$ is commonly used as a cut-off criteria to select the principal components that account the major percentage of variance, as defined by Kaiser in [30]. As pointed out by Kassambara in [31], there is no well-accepted objective way to automatically define the number of PCs to consider in a multivariate analysis. In the case of this study, $\lambda_{i}>1$ is a sufficient criteria to select the PCs. The selection of variables to describe the principal components is basically based on two parameters: $\cos ^{2}$ and contribution. $\cos ^{2}$ represents the quality of projection of the variables on the chosen principal components plane. Each principal component, a latent variable, is characterized by the observed variables as follows:

- Dim 1 is mainly defined by the GDP, electricity consumption and urban population. These variables represent the socio-economic situation.

- Dim 2 is characterized by the area, population, and hydropower production

- Dim 3 is a function of the isolation index, the share of renewable energy and electricity consumption. The variables contain useful information regarding the electricity vulnerability of the islands.

These variables were selected because they both have a good quality of projection $\cos ^{2}$ and an appreciable contribution to each principal component construction.

As shown in Figure 2, most of the islands have some mid or mid-low values for the two dimensions. The right part of the plan represents islands with high socio-economic values. The decomposition of the total inertia on the components of the PCA suggests focusing the study on the first two components. Indeed, these axes reveal a higher inertia rate than the 0.95 quantile of random distributions $(50.75 \%$ versus $40.17 \%)$. The high part of the plan is mainly characterized by high area and population values. Saint Dominica, Singapore, Papua New Guinea and Cuba are the four islands that are separated from the cloud of islands. Thus, we could conclude that the major islands encompass a rather small area and have some similar features. Most of these small islands have a low share of renewable energy in their electricity mix. Moreover, the isolation 
Figure 2: 2010 SIDS projection on the first and second principal components.

(a) Graph of individuals

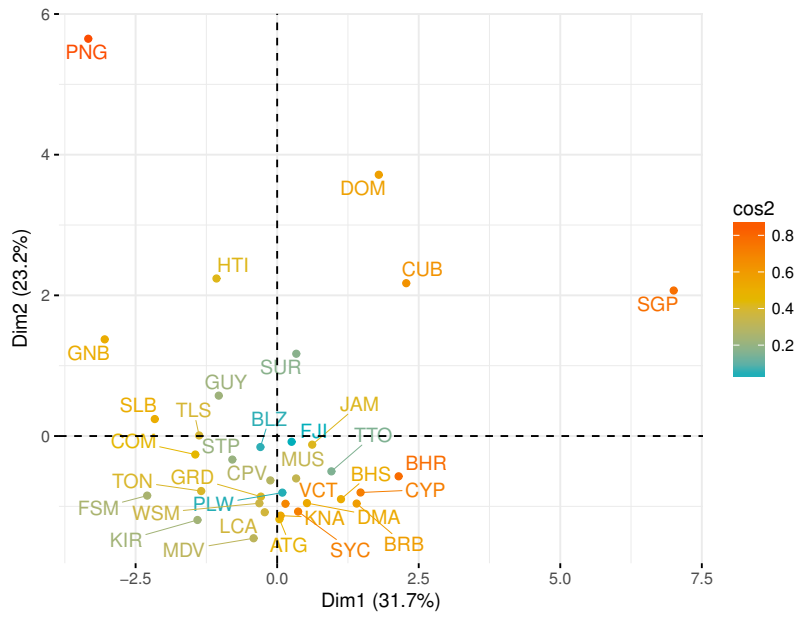

(b) Variable correlation plot

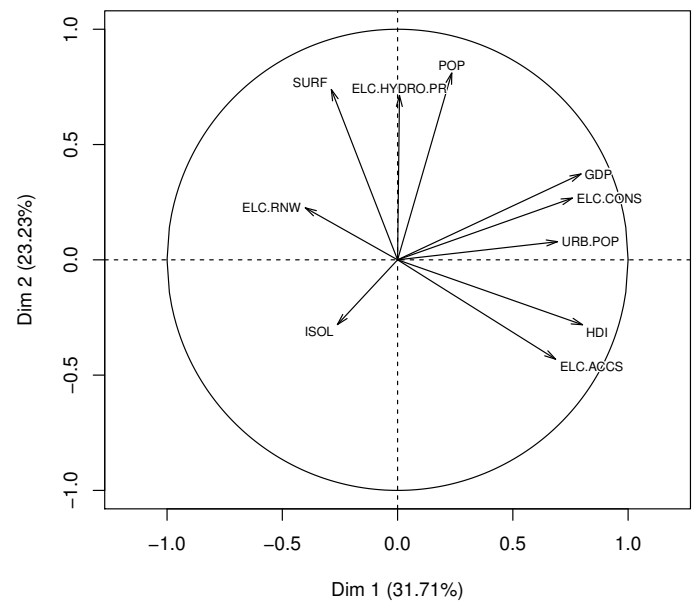

index has worsened the energy vulnerability of these small remote territories. The graph analysis highlights two singular individuals, Papua New Guinea (PNG) and Singapore (SGP), which mainly contribute to the construction of the plan $(50.1 \%)$. Indeed, PNG is mainly characterized by very high values for surface area, hydropower and the share of renewable energy. This island also has a singular situation with a low electricity rate $(19.5 \%)$. Singapore's specifics include the highest values for gross domestic product, urban population and electricity consumption. A second PCA has been investigated without these two particular islands. This new PCA, whose results are shown in Figure 3 with clustering, displays a representation of $32.2 \%$ on dimension 1 and $18.5 \%$ on dimension 2 .

\subsection{Hierarchical clustering analysis}

In the next step, hierarchical clustering on the main components of the factor analysis has been performed. The partitioning method is based on the K-means method, which is one of the most commonly used clustering algorithms. In this approach, the cluster is represented by its center of gravity. The main idea of this technic is to minimize the total within-cluster variation. This iterative method always converges to a solution, [32]. The optimization of the number of clusters was carried out using the gap statistic method, which provides a statistical approach instead of a global measure such as the elbow or average silhouette method, [33]. The gap statistic compares the total within intracluster variation from the original data with a generated reference data set,[34].Assuming that normal distributions could represent the data, a reference dataset, $E_{n}^{*}\left\{\log \left(W_{k}\right)\right\}$, is obtained using Monte Carlo sampling. The Gap statistic is therefore defined as,

$$
\operatorname{Gap}_{n}(k)=E_{n}^{*}\left\{\log \left(W_{k}\right)\right\}-\log \left(W_{k}\right)
$$

Where $W_{k}$ is the total within sum of square for a given k clusters. As shown in Figure 3, the optimal number defined by gap statistic is 3 .

Each cluster can be summarized by the categorical variables linked to them, [35]. These variables are identify by a significant p-value of $<0.05$. The description of each cluster is recapitulated as follow:

- Cluster 1: Urban population, electricity access and HDI are the three variables that define this cluster with low value for each parameter. This cluster represents the most vulnerable islands, where poverty and unemployment are very high, intensified by an high dependency on fossil fuel. The exception is 
Figure 3: 2010 SIDS hierarchical clustering.

(a) Clustering projection on the first principal components

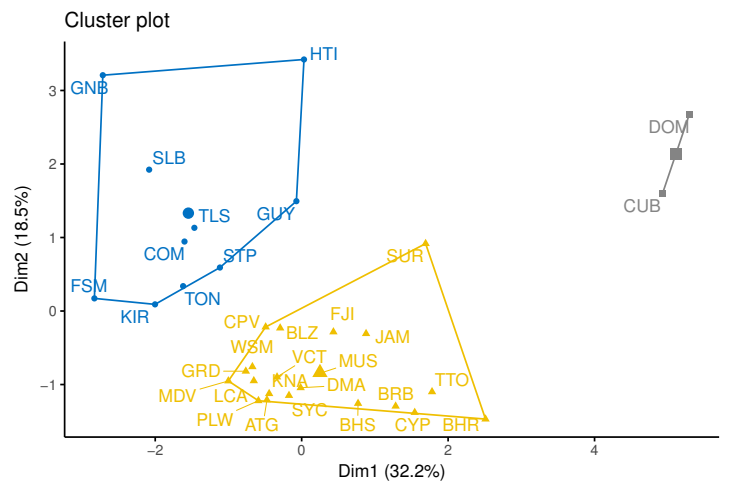

(b) Optimal numbers of clusters $\mathrm{k}=3$

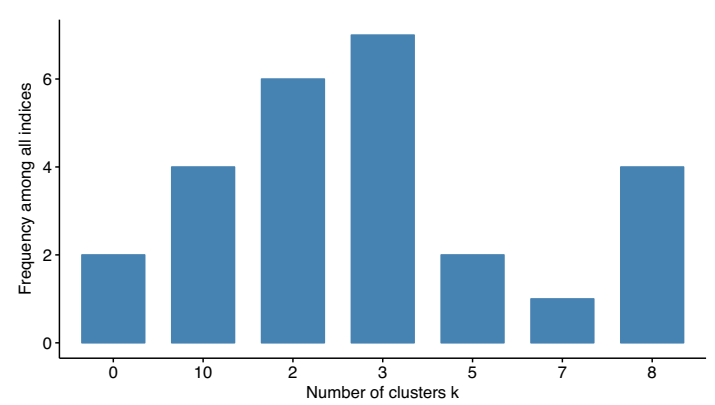

Guinea Bissau, for which electricity production is essentially based on geothermal energy: in 2010 and 2014, the electricity production of Guinea Bissau depended respectively on $96.03 \%$ and $97.42 \%$ of geothermal energy (IEA data). Timor Leste represents the average behavior of the cluster.

- Cluster 2: With the largest numbers of island, this cluster is characterized by a small population but high electricity access and HDI level. These territories have middle or upper middle income economies [36] [37]. The paragon of Cluster 2 is Mauritius.

- Cluster 3: Comprising only Cuba and Dominica, this cluster is mainly defined by the GDP, population, and hydropower. The mean values in these categories are much higher than the overall mean. Even if variables such as HDI seem low, Cuba and Dominica have shown a large improvement since the 1990s owing to high standards in education and health care.

As the hierarchical clustering highlights, there is a large discrepancy between the three clusters. Thus, the sustainability of the islands cannot be understood using only to the economic dynamics of the territories or their dependency on fossil fuel.

\subsection{Sustainability index}

The proposed indicator depicted in the following paragraph is based on the PCA analysis. The first four components are considered, as their eigenvalues are greater than 1 and summarize $73.44 \%$ of the overall information contained by the data set. The result of the sustainability index is shown in Figure 4 . Even if it were possible, the objective was not to rank the islands but to observe the dynamics of transition within a short period and understand whether the transition is actually ongoing.

It can be clearly noted that most of the islands (23 of 35 ) have become more vulnerable during the 2010-2014 time span. These relative dynamics are particularly observable for Tonga, the Seychelles, the Maldives and Saint Kitts and Nevis, as their decreases in sustainability are the most important. These islands have experienced an increase in their urban populations and, simultaneously, a decrease in GDP. Their vulnerability is mostly due to their significant dependency on oil consumption for electricity generation, as no renewables sources have actually been developed. There are four cases (Singapore, Cuba, Dominica, and Bahrain) that are also singular with the lowest sustainability index. These cases are characterized by a very high electricity consumption compared to the other islands, with no or a low integration of renewables. These island have fast growing economies that have induced the deployment of a high energy intensity in the territories. For the observed year, Singapore was still the least sustainable country, and the situation is continuing to worsen.

Thus, the global variation in the sustainability of the islands is heterogeneous, with a mean variation of 0.059 \pm 0.061 . These results highlight the disparity of these territories and the difficulty in defining a common 

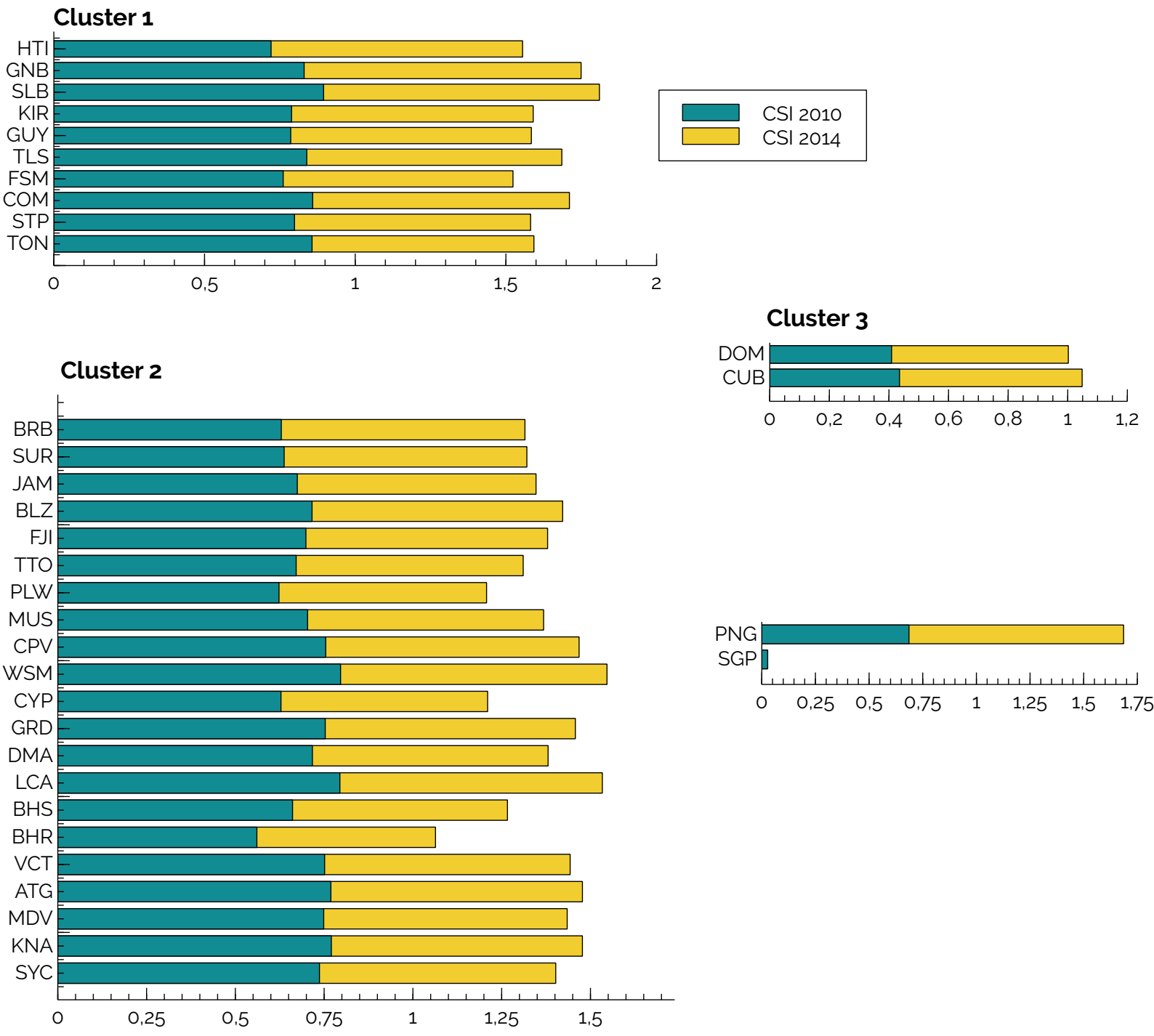

sustainable plan for the future. Focusing on the cluster, we observe that between 2010 and 2014, Cluster 1 has become more vulnerable. The underlying reason is the growth of two correlated variables (population and electricity consumption) for most of the islands of this cluster. At the same time, Cluster 2 comprises islands that have increased their sustainability, even if they have set in motion a new set of dynamics based on the economy and green electricity development. Finally, Cluster 3, comprising Cuba and Dominica, has developed hydropower plants and other RES (for Cuba). However, these islands exhibit low sustainability performances because of their electricity demand growth. In these two cases, the response to an increase of $15 \%$ in electricity has been an approximate $3-4 \%$ increase in the share of fossil fuel in the electricity mix. These analyses have shown the three main situations (described by cluster) and the three main dynamics for a sustainable transition. SIDS are and will be the first to suffer from the effects of climate change, but they must also seize the opportunity to be the first to succeed in the challenge of transitioning to a sustainable situation. To plan a sustainable future, much effort must be rapidly made to limit the use of fossil fuel 
resources while economically developing these islands. Due to their size, it will probably be difficult to carry real weight in the decisions of the international community, but as our exploratory data analysis has shown, some SIDS have some similarities and could be clustered. However, high contrasts are observable, as poor territories, such as Tonga, Haiti, and Guinea-Bissau, are opposed to countries that score over 0.8 for HDI, such as Bahrain, Cyprus and Singapore. The composite index gives elements that suggest which parameters are significant for policy strategy to enhance the islands' sustainability.

\section{Conclusion}

The purpose of this study was to analyze the sustainability of the SIDS by creating a composite index (SI). The SI attempts to easily measure the level of sustainability of various islands over time. Such an index in this form is accessible to interested agencies and policymakers and helps direct efforts toward improving the deployment of RES in the energy mix for a sustainable territory. The main assumption of the paper was to build an index based on variables that are easy to evaluate. Our purpose was to base the indicator on a multivariate analysis in order for the quantitative data to have a significant influence in describing the sustainability of these islands.

The weights were assigned by the calculation of the variance of each principal component. The first lesson learned from this study is that many islands are not marching toward a sustainable energy transition. Most of them are highly dependent on oil imports for their electricity generation. Thus, it seems clear that policymakers favor the development of fossil fuel systems to address the increase in energy demand, even if the islands have considerable potential for the development of renewable sources. As these remote territories are greatly vulnerable to exogenous shocks, such as oil price volatility, this worrying situation must be a key point for truly investigating and devising a road map for a successful energy transition. Furthermore, this short time evolution is a real indicator of the variability of islands' situations. Thus, energy planning should not be only for a long-term scenario but also for short term (less than 5 years) dynamic changes in order to permanently adjust the energy scenario. The variability in islands' situations obliges their specific characteristics in different scenarios to be taken into account. It is also crucial to remain vigilant to any inflexion in the trend in a short time span for prospective modeling.

\section{Acknowledgments}

The authors gratefully acknowledge the financial support of the TRANSEETER research project, from the University of Reunion Island through the Incentive Research Fund program for Energy Transition.

\section{References}

[1] G. Bel, S. Joseph, Climate change mitigation and the role of technological change: Impact on selected headline targets of europes 2020 climate and energy package, Renewable and Sustainable Energy Reviews 82 (2018) 3798-3807. doi: 10.1016/j.rser.2017.10.090. URL https://doi.org/10.1016/j.rser.2017.10.090

[2] D. D. Wang, T. Sueyoshi, Climate change mitigation targets set by global firms: Overview and implications for renewable energy, Renewable and Sustainable Energy Reviews 94 (2018) 386-398. doi:10.1016/j.rser.2018.06.024. URL https://doi.org/10.1016/j.rser.2018.06.024

[3] M. Pacesila, S. G. Burcea, S. E. Colesca, Analysis of renewable energies in european union, Renewable and Sustainable Energy Reviews 56 (2016) 156-170. doi:10.1016/j.rser.2015.10.152. URL https://doi.org/10.1016/j.rser.2015.10.152

[4] S. O. Tan, T. Toku, İ. Türker, The analysis of renewable energy researches in turkey, IOP Conference Series: Materials Science and Engineering 161 (2016) 012077. doi:10.1088/1757-899x/161/1/012077. URL https://doi.org/10.1088/1757-899x/161/1/012077

[5] V. Angeon, P. Saffache, Les petites économies insulaires et le développement durable : des réalités locales résilientes ?, Etudes caribéennes (11) (2008) En ligne.

URL http://etudescaribeennes.revues.org/3443

[6] C. Bouchard, L. Marrou, S. Plante, R. P. Payet, E. Duchemin, Les petits États et territoires insulaires face aux changements climatiques : vulnérabilité, adaptation et développement, VertigO- La revue électronique en sciences de l'environnement 10 (3) (2010) En Ligne. doi:10.4000/vertigo.10634.

URL http://vertigo.revues.org/10634 
[7] V. Angeon, J.-F. Hoarau, Les petites économies insulaires : un monde à part entière? Nouveaux regards conceptuels et méthodologiques, Région et Développement 42 (2015) 5-13.

[8] F. Benard-Sora, J. P. Praene, Les Petits Etats Insulaires en Développement face au défi de la transition énergétique : entre forces et faiblesses, étude de leur vulnérabilité, in: "Les défis de développement pour les villes et les régions dans une Europe en mutation" ASRDLF-ERSA, Athènes, Grèce, 2017, p. 24.

[9] UNESCO, Small Island Developing States - UNESCO's Action Plan, Tech. rep. (2016). URL http://unesdoc.unesco.org/images/0024/002460/246082E.pdf

[10] F. Wolf, D. Surroop, A. Singh, W. Leal, Energy access and security strategies in small island developing states, Energy Policy 98 (2016) 663 -673. doi:https://doi.org/10.1016/j.enpol.2016.04.020. URL http://www.sciencedirect.com/science/article/pii/S0301421516301884

[11] J. P. Praene, M. H. Radanielina, V. R. Rakotoson, A. L. Andriamamonjy, F. Sinama, D. Morau, H. T. Rakotondramiarana, Electricity generation from renewables in madagascar: Opportunities and projections, Renewable and Sustainable Energy Reviews 76 (2017) 1066 - 1079. doi:https://doi.org/10.1016/j.rser.2017.03.125.

URL http://www.sciencedirect.com/science/article/pii/S1364032117304604

[12] E. Michalena, J. M. Hills, Paths of renewable energy development in small island developing states of the south pacific, Renewable and Sustainable Energy Reviews 82 (2018) 343 - 352. doi:https://doi.org/10.1016/j.rser.2017.09.017. URL http://www.sciencedirect.com/science/article/pii/S1364032117312467

[13] P. Encontre, The vulnerability and resilience of small island developing states in the context of globalization, Natural Resources Forum 23 (3) (1999) 261-270. doi:10.1111/j.1477-8947.1999.tb00914.x. URL https://doi.org/10.1111/j.1477-8947.1999.tb00914.x

[14] L. Briguglio, Small island developing states and their economic vulnerabilities, World Development 23 (9) (1995) 16151632. doi:10.1016/0305-750x (95)00065-k. URL https://doi.org/10.1016/0305-750x(95)00065-k

[15] M. Dornan, F. Jotzo, Renewable technologies and risk mitigation in small island developing states: Fiji's electricity sector, Renewable and Sustainable Energy Reviews 48 (2015) 35-48. doi:10.1016/j.rser.2015.03.059. URL https://doi.org/10.1016/j.rser.2015.03.059

[16] Y. Kuang, Y. Zhang, B. Zhou, C. Li, Y. Cao, L. Li, L. Zeng, A review of renewable energy utilization in islands, Renewable and Sustainable Energy Reviews 59 (2016) 504-513. doi:10.1016/j.rser.2016.01.014. URL http://www.sciencedirect.com.elgebar.univ-reunion.fr/science/article/pii/S1364032116000423

[17] H. C. Gils, S. Simon, Carbon neutral archipelago 100\% renewable energy supply for the Canary Islands, Applied Energy 188 (2017) 342-355. doi:10.1016/j.apenergy.2016.12.023. URL http://www.sciencedirect.com/science/article/pii/S0306261916317871

[18] N. Duić, G. Krajačić, M. da Graça Carvalho, RenewIslands methodology for sustainable energy and resource planning for islands, Renewable and Sustainable Energy Reviews 12 (4) (2008) 1032-1062. doi:10.1016/j.rser.2006.10.015. URL http://www.sciencedirect.com.elgebar.univ-reunion.fr/science/article/pii/S1364032106001560

[19] H. Bossel, Indicators for sustainable development : theory, method, applications, International Institute for Sustainable Development, Winnipeg, Man, 1999.

[20] K. U. Shah, P. Blechinger, H. Furlonge, G. Philippidis, D. Surroop, A. Singh, Editorial: Special issue on energy policy for the future of small island developing states (SIDS), Energy Policy 98 (2016) 650-652. doi:10.1016/j.enpol.2016.09.007. URL https://doi.org/10.1016/j.enpol.2016.09.007

[21] UN-OHRLLS, Un office of the high representative for the least developed countries, landlocked developing countries and small island developing states, http://unohrlls.org/about-sids/country-profiles/ (2018).

[22] F. Taglioni, Les petits espaces insulaires face à la variabilité de leur insularité et de leur statut politique, Annales de géographie 652 (6) (2006) 664. doi:10.3917/ag.652.0664. URL http://www.cairn.info/revue-annales-de-geographie-2006-6-page-664.htm

[23] F. Doumenge, Les îles et les micro-États insulaires, 1985.

[24] D. Ndiaye, K. Gabriel, Principal component analysis of the electricity consumption in residential dwellings, Energy and Buildings 43 (2-3) (2011) 446-453. doi:10.1016/j.enbuild.2010.10.008. URL https://doi.org/10.1016/j.enbuild.2010.10.008

[25] A. A. Romano, G. Scandurra, A. Carfora, R. V. Pansini, Assessing the determinants of SIDS' pattern toward sustainability : A statistical analysis, Energy Policy 98 (2016) 688-699. doi:10.1016/j.enpol.2016.03.042. URL http://dx.doi.org/10.1016/j.enpol.2016.03.042

[26] E. Gupta, Oil vulnerability index of oil-importing countries, Energy Policy 36 (3) (2008) 1195-1211. doi:10.1016/j. enpol.2007.11.011.

URL https://doi.org/10.1016/j.enpol.2007.11.011

[27] E. Gnansounou, Assessing the energy vulnerability: Case of industrialised countries, Energy Policy 36 (10) (2008) 37343744. doi:10.1016/j.enpol.2008.07.004. URL https://doi.org/10.1016/j.enpol.2008.07.004

[28] J. Burck, C. Bals, S. Ackermann, The climate change performance index: background and methodology, Germanwatch, 2009.

[29] S. Lê, J. Josse, F. Husson, FactoMineR: A package for multivariate analysis, Journal of Statistical Software 25 (1) (2008) 1-18. doi:10.18637/jss.v025.i01.

[30] H. F. Kaiser, A NOTE ON GUTTMANs LOWER BOUND FOR THE NUMBER OF COMMON FACTORS1, British Journal of Statistical Psychology 14 (1) (1961) 1-2. doi:10.1111/j.2044-8317.1961.tb00061.x. URL https://doi.org/10.1111/j.2044-8317.1961.tb00061.x 
[31] A. Kassambara, Practical Guide To Principal Component Methods in R (Multivariate Analysis) (Volume 2), CreateSpace Independent Publishing Platform, 2017.

[32] J. Macqueen, Some methods for classification and analysis of multivariate observations, in: In 5-th Berkeley Symposium on Mathematical Statistics and Probability, 1967, pp. 281-297.

[33] F. Husson, S. Le, J. Pags, Exploratory Multivariate Analysis by Example Using R, Second Edition (Chapman \& Hall/CRC Computer Science \& Data Analysis), Chapman and Hall/CRC, 2017.

[34] R. Tibshirani, G. Walther, T. Hastie, Estimating the number of clusters in a data set via the gap statistic, Journal of the Royal Statistical Society: Series B (Statistical Methodology) 63 (2) (2001) 411-423. doi:10.1111/1467-9868.00293. URL https://doi.org/10.1111/1467-9868.00293

[35] F. Husson, Analyse de donnees avec R, Presses universitaires de Rennes, Rennes, 2016.

[36] W. Bank, The world bank data : Upper middle income, https://data.worldbank.org/income-level/upper-middle-income (2018).

[37] W. Bank, The world bank data : Middle income, https://data.worldbank.org/income-level/middle-income (2018). 